\title{
Emotional Engagement and Active Learning in a Marketing Simulation: A Review and Exploratory Study
}

\author{
Kear Andrew, Bown Gerald Robin \\ The Business School \\ University of Gloucestershire, Gloucestershire, UK
}

\begin{abstract}
This paper considers the role of emotional engagement during the use of a simulation. This is placed in the context of learning about marketing. The literature highlights questions of engagement and interactivity that are entailed in the use of these simulations. It is observed here that both the anticipation of and the process of engagement with the simulation generate emotional responses. The evidence of emotional anticipation was collected through the use of vignettes and a short survey. The production of negative emotions before and after the activity was observed and considered. The particular occurrence of these emotions on the development of understanding is then discussed. There is general evidence for the mundane reality of such simulations that support learning and group engagement. The connection with activity theory was explored and proposed as a potential theoretical fit with the evidence.
\end{abstract}

Keywords-component; Learning; Simulations; Feedback; Emotional Learning Scenarios; Emotional Anticipation; Deep Learning; Vignette Research

\section{LEARNING AND ENGAGEMENT}

The authors have been involved in the delivery of a marketing simulation exercise to undergraduate students at a British university. This course forms one module of the undergraduate programme, often delivered in the second or third year. It is traditionally considered that the value of these simulations resides in the ability to give a different learning experience to the participants [32]. The same authors consider that the student's characteristics should be taken into account. Importantly for this paper these characteristics are considered to be multivariate. The perspective of this paper is to examine this assumption and to increase the understanding of the processes involved in using simulations in a learning environment. The proposition examined in this paper is that the achievement of active learning can be dependent on the mundane nature of situated understanding [20]. The emotional placement prior to the simulation will also be explored. The appearance of negative emotional responses and the connection with the generation of increased attentiveness will be further explored and elaborated in this paper.

In the past the structure of the learning environment was often taken for granted. During the early 1990's studies revealed that students found the traditional, didactic lecture to be their least favourite [4]. Students were found to be more willing and enthusiastic about taking a more active role in the lecture according to Ref. [36]. The teaching and learning strategies adopted here are meant to assist the student in becoming a 'critical being' [3]. In this view the student attains the ability to determine the critical reason for a particular course of action or method, achieves a critical level of self-reflection and review of contextual history of the self, and finally becomes able to undertake a critical action that is based upon problem solving at the skills level. As a result of this problem based learning students were required to take a deep approach to learning [24]. As these ideas developed the idea of interactive lectures was found to be more enjoyable than traditional lectures [9]. Whilst the didactic lecture is still with us the development of technology has an impact in improving engagement, both within the lecture format [16], and also in the production of deeper learning [33]. Ref. [19] suggests that experiential simulations and class room games are an effective way to increase the attentiveness of students. This increased awareness and elaboration of their own unrehearsed behaviour may cause them to rethink their engagement through the importance of tactical decisions and overall strategies employed. This leads to the generation of further ideas about the idea of engagement which is now more prominent in these discussions than the idea of criticality mentioned above. Technology is something that we are required to interact with, but it has been argued as more than a system for delivery; there is still the need to build relationships for learning [11]. Ref. [12] suggests that the increase in student engagement can be attained through creativity and emotional engagement.

According to Ref. [19] the effectiveness of simulations is primarily achieved in engaging the whole student and not just their intellect and analytic powers. This emotional engagement is often considered in terms of psychological approaches to emotional and cognitive learning. Previously there had been some reluctance within higher education to include the engagement of emotions into the learning space where it had been described as 'inappropriate territory' [22].This coincided with a challenge to the primacy of rationality in learning, thus preventing what some see as the development of the transcendental nature of rational understanding in a life world [2]. This previously 'inappropriate territory' has more recently become an important dimension of learning that can significantly enhance students' engagement with learning and assessment [27]. It may be the case that the preference for such learning is driven by novelty but it can be noted that a significant amount of research points to the value of an emotional content in the development of learning. 
Starting from the tenet that we need to improve and refine the overall learning experience of students this creates an obligation to consider further some fundamental approaches to learning. One of these is the concept of interactivity. It is generally considered that improving learning can be achieved through the promotion of either interactivity [9] or transformative learning [26]. The idea of interactivity often evades a definition but is commonly used in the discussion of computer mediated environments. Ref. [38] in discussing interactivity, consider the device- and message-centric approaches to this idea before deriving from the literature a fourfactor taxonomy of bi-directionality, timeliness, mutual control and responsiveness. Interactivity, in their formulation is generated through computer mediated communication (CMC) thus indicating the assumptions of this approach. This communicative framing of the concept of interactivity in this context needs to be developed in tandem with a learning perspective. In considering transformative learning [35] has previously noted that the empirical basis for transformative theory requires some further investigation into the contexts where it is fostered. The approach of transformative learning is operationalized as 'an epistemology of evidential and dialogic reasoning' [26]. The fit with interactivity is made in that this epistemology emphasises the dialogic/communicative aspects of learning. According to Ref. [31], in their findings offer support that tools for transformational learning are providing students with learning experiences that are 'direct, personally engaging and stimulate reflection upon experience' [36]. The authors here suggest that there may be some transformative currency in the use of a simulation but it is considered that the process of transformational learning requires some mediation for it to develop. This mediation can be the inspirational lecture, or through peer participation, but often some form of artefact is needed to enable this learning [15].

\section{LEARNING AND SIMULATIONS}

The artefact in this case is the computer simulation which often presents itself as a constructed object as the focus of the activity. There have been some studies on learning with simulations. Research by Ref. [18] found that students did in fact learn by participating in a simulation and the simulation was both enjoyable and perceived to be worthwhile. According to [21] students perceive simulations as being (1) engaging, (2) useful, (3) effective learning tools, and (4) effective in promoting teamwork. Students' perceptions of computer-based simulation team dynamics and their positions on the use of simulations and simulation performance was researched by [1] who found that student team cohesion and student team independence strongly influenced their perceptions of the use of computer based simulations. The other aspect that is worthy of note here is the role of the instructor or facilitator, who provides interpretation for the groups when requested. There is available an instructor in the simulation forum who can be considered to be both a narrator and also a guide. The latter role becomes prominent in the respect that they have travelled this way before. The specific role of instructors is likely to differ among simulation types but could be considered as providing feedback and guidance on the simulation and how to use it. In relation to the particular marketing simulation here, Markstrat, the role is to draw student's attention to the outcomes of their decisions and subsequent performance relative to their competitors; often in a narrative form. So the dialogic learning here occurs in two directions, the intra group dialogue and the dialogue between the group and the facilitator. Research into the use of other marketing simulations such as Capism [6] offer an opportunity to operate virtual companies making decisions concerning marketing, production, finance, human resources, TQM and ethics. Here some students were taught how to use the simulation and coached by a professional. This increased performance when compared with a control group that were left to make decisions on their own. The findings indicated that the use of a business professional into the classroom improves the ability of students to make decisions. This seems to confirm the expectation that an effective instructor will improve learning.

It may be that the development of interactivity is now linked to the preferred mode of learning for a particular generation. According to Ref. [34] current undergraduate business students as members of generation $\mathrm{Y}$ have shorter attention spans and desire interaction and stimulation resulting in student engagement becoming more important. So in this respect a challenging environment provides students with an arena whereby they can thrive [34]. Generation Y are further characterised by having lived their entire lives with technology such as computers, mobile devices and video games. An increased level of "gaming", which is deemed to be characteristic of the activities expected by this generation, results in the need for educators to develop forms of engagement which are suitably commensurate with this mode of being.

Returning to the view of the simulation as an artefact based activity the ideas of activity theory consider 'that object orientated actions are always, implicitly or explicitly, characterised by ambiguity, surprise, interpretation, sensemaking and potential for change' [8]. Central to this view is that 'an activity system is by definition a multi-voiced formation' [7]. In considering the role of artefacts in collaborative virtual environments (CVE's) [30] proposes that much can be learnt through the division of the learning environment into outlook, structure, and roles. The authors of this paper develop this idea in terms of an immersive computer environment which relies on the employment of artefacts for communication facilitation and task accomplishing. The simulation discussed here creates its own artefacts, such as screen presentations and reports, but in the occupation of a physical classroom. The participants are also collected into groups for the performance of the mediated task which affects the communicative and multi-voiced aspects of the CVE. In seeking to enhance this idea of active engagement in the development of learning this paper will develop the idea of interactive communicative environments (ICE).

The roles occupied by the participants of this research are to a significant extent driven by their approach to the task. Whilst Ref. [14] asserts that active learning can generate a positive emotional response that instigates an 'attentiveness that enriches understanding' and which can enhance self-esteem and a sense of empowerment [17]. There is, however, little research that investigates the effect of negative emotional response and its impact on attentiveness that enriches understanding. The attentiveness here is not considered to be in the transcendental domain of consciousness but to contain the elements of activity and engagement often developed by the incidence of ambiguity. 
The structure of this simulation is the development of interactivity with the artefact. This interactivity can be an attribute that is more closely associated with the 'reality of business life'; however defined. Ref. [28] suggested that computer technology such as simulations can be used to create authentic assessments that mirror real world scenarios. Related to active learning is the generation of deep learning as a result of the simulated experience and linking a taught theory such as segmentation, targeting and positioning (STP) to the 'real' world resulting in the challenging of preconceptions [14]. According to Ref. [24] the type of test that is anticipated will determine the level of learning undertaken by the students. As such it is deemed beneficial to explore the thoughts of the participants before they interact with the simulation. It is worth noting at this point the nature of business activity, which is often characterised by periodic reporting of performance and the business simulation offering the same process of periodic reporting. This develops a rational and reflective processing of information, within a dialogic group dynamic as discussed earlier. Other programmes such as role playing games offer continuous incremental feedback.

It is suggested that active learning can create an enhanced affective response [14]. This is supported by the findings of Ref. [31]; one participant in their research stated that 'You can't develop a real understanding until you experience it personally.' According to Ref. [5] getting students committed, via small group exercises, and other active strategies, to owning the material. This, it is proposed, results in the students becoming more effective learners who are more likely to achieve the learning outcomes of the lecture. The learning is often considered to reside at the level of skills, which are often demanded by employers [10]. Therefore the structured approach to teaching and learning strategies is strongly based upon active learning and the implicated engagement with artefacts. The extent to which active learning generates an affective response and is moderated by the use of artefacts and dialogic reasoning will be considered in this piece.

\section{BACKGROUND TO MARKSTRAT (SIMULATION)}

The simulation used was the marketing simulation Markstrat. This is employed in a $2^{\text {nd }}$ year undergraduate module in Marketing management. The simulation can be operated with 4 , 5 or 6 companies operating in 2 product markets within consumer electronics. The students work in teams of between 4 and 6 team members and are assigned to control and make decisions for one of the companies for 6 rounds (the equivalent of 6 years). With the Markstrat simulation there are clear and visible outcomes to the decisions made via a brand map displaying the position of customer segments, the position of the company's brands and the key dimensions for improving positioning. The rounds last for approximately 1 hour and 30 mins and the feedback of the decision making of the teams is then analysed and reported back visually via a projector. This meant that all teams could compare their decision making with their peers who are running competing firms. Furthermore the students were prepared for the simulation by undertaking a number of case analyses that aimed to build the students' knowledge in relation to the type of decisions that they would be making. Whilst there are many uses for simulations in higher education Ref.[28] explored how simulations could be used as assessment tools. They suggest based on their findings that simulations work by helping students to master knowledge and skills and that they work well with formative assessments. In the Markstrat simulation assessments are based upon the student's perceptions of the outcomes of their decision making and overall understanding of key concepts in relation to their performance. The same authors find that a conceptual framework and supporting learning materials are necessary to support student learning. The Markstrat simulation is underpinned by the marketing and branding conceptual framework on which the literature is vast. The Markstrat simulation is a simulation with a web-based interface and a brief summary of its operation is given here. The teachers / experts provided expertise on how to run the simulation and where to find and how to use typical marketing data to underpin their decisions. The students are in groups of 4 or 5 and have to operate a company and its brands in 2 markets with a total of 8 segments ( 5 segments in market 1 and 3 segments in market 2). All teams start in identical points regarding performance and positioning. As such the students have to make tactical decisions for each of their brands. The results of these decisions are presented periodically and include profits (overall and per brand), turnover, market shares, stock price index, inventory costs, awareness etc. The results are also communicated in a comparative form, group performance is judged to be better or worse than the other participants. The simulation had been previously found to enhance learning through active engagement and as such the authors wished to identify why and how the use of a simulation could improve the active learning within the business school.

The overall aim was to illuminate the decisions that have to be made to manage marketing in a competitive context. The aim and description of the simulation can be taken from the website:

"Markstrat offers MBA students and professionals a riskfree platform for testing theories and making decisions. From competitive forces to the effects of sales, distribution, $R \& D$ and advertising, every aspect is real ... The competition is real, but so is the teamwork. "[23]

This description nicely sets up this research project as it identifies the 'reality' of the game and the elements of teamwork that are integral to its operation.

\section{RESEARCH METHODS}

It was decided to approach this research by trying to discover the emotional placement of the students in respect of the simulation exercise. The idea was to explore the mundane nature of situated understanding [20] which is conceived to be a transcendence of the emotional and intellectual division. The anticipation of the exercise has also been noted as a significant factor. If this simulation incorporated the elements of activity theory discussed above the potential for it to create this ambiguity and surprise would be anticipated by the participants. The methodology was designed to produce an evoked awareness of the situation that the participants were about to enter. To explore this situation of created anticipation a student cohort were, in the first instance, given some scenario sketches [37] about imaginary predecessors on this particular course. In order to generate a response that could address a situated understanding, the students were given a sheet which contained 4 descriptions of students that might be facing this simulation 
exercise. The descriptions were about 100 words long and presented the ideas of complication, speed and timeliness, group work, management of unpredictability, and a sufficing approach.

This methodology allowed students to adopt a description that suited their feelings and also allowed a sensitisation to the arising issues in the conduct of the simulation. The scenarios or vignettes, were also designed to be short thus enabling a quick completion of the task. The rapid response was designed to facilitate an emotional rather than an intellectualising response and such vignettes have been used in illustrative research [25].

The students were asked to see which description matched their own situation and comment on their own words. They were also asked after the simulation whether they still agreed with what they said before, and what advice they would give to the subsequent group. There were 91 students in the cohort, 61 gave a response and 30 agreed with one of the descriptions offered.

$\begin{array}{clc}\text { Description } & \text { Number } & \text { Percentage } \\ \text { Stephen } & 6 & 20 \% \\ \text { Kirsty } & 1 & 3.33 \% \\ \text { Jayne } & 16.5 & 55 \% \\ \text { Kevin } & 6.5 & 21.67 \% \\ \text { Total } & 30 & \end{array}$

\section{FINDINGS AND ANALYSIS}

The written comments were now studied. More students had provided comments than had chosen a scenario (61 to 30). From an initial visual inspection of the words used in the comments it seemed that the responses could be grouped under six headings. These were; The ability to achieve results, the enjoyment of participation/interaction, the problem solving focus, the interesting/engaging nature of the task, the uncertain nature of the task, and the idea of task novelty. The initial textual analysis found that the first and the last were areas where the least comments were made. The few comments on the ability to achieve were 'we're going on to win', 'how I will achieve success' and 'interactions are vital to achieve success'. The comment about personal success in a group assignment is interesting and the comments about success have been incorporated in a revised analysis. It is possible to conclude that the elements of overt competition were not articulated to a great extent, and this might provide support for the elements of anticipation and ambiguity, so not quite knowing what to expect. The idea of the different nature of the simulation garnered few comments that were difficult to separate from other areas. Several comments about this task being different due to its practical nature seemed to say something more than merely contrasting the difference from the standard learning situation. There was one comment about the nature of this task being different because it required the group to brief the next group but there were few comments of this nature.

There were a number of comments about the uncertain nature of the task. These contained comments such as 'working outside the box' and thrown in at the deep end'. It seemed that the comments that indicated difficulties with control belonged here. The task was 'overwhelming' and 'unpredictable'; 'I do not know what's coming' 'not knowing what to do' 'what to expect' 'will I be able to cope'. The time was a factor in the espoused uncertainty 'not much time' 'complicated and speedy decisions' were required. 'I am overwhelmed about the task ahead'. It is possible to see these comments in terms of anticipation.

Under the category of interesting several of the comments were of the form that this was 'an adventure' 'something new' 'looking forward to what it can teach me' 'it is active not reflective'; they saw the novelty of the exercise. The task to some seemed also to be created to conceal. It was 'unclear' 'there were a lot of what ifs' 'I didn't really understand'. It was also said that 'you can use the knowledge you have gained beforehand'. It was an opportunity therefore to use some of the instructional teaching in a 'practical' forum. This practical artefact-based activity with the simulation becomes explorative; the exploration of being effective in the situation given.

The problem solving approach seemed to focus on decision making in what was perceived to be a real situation. The 'real' nature of the task was mentioned by a significant number of the participants. So it was 'unpredictable - more realistic' 'theory and problem solving in situ' 'real business decisions - real life'. The judgmental nature of the task was identified; 'put in a position where you have to make a judgment call' 'the effect of one decision on the next' 'having to make decisions' 'simulation is a different concept of learning - an idea about decisions'. One of the participants talked about the role of luck in decisions but a later view, after the simulation, talked about 'an informed prediction' being a better description. One of the scenarios talked about man vs machine and this was picked up by one who felt that the machine had been programmed by man. So it was a constructed situation.

Those that expressed the view that this was enjoyment through interaction were all those who enjoyed 'making decisions in a group'. This exercise was seen as 'clever and exciting' presumably more so than the tasks they were currently faced with. This was the sort of activity that was 'open to different views', this needed a consensus to make it work. The collaborative nature of the task here was more important than the decision making.

The six initial interpretations which were discernable in this research seemed to reside in the same domain as those given for activity theory. There was evidence that the participants looked forward to the dialogic nature of learning. As most of these participants were from Generation $\mathrm{Y}$ who are considered to value independence [13] there was a significant level of apprehension about the exercise, which seemed to be in contrast to theory based exercises. Ref. [13] also explores the incidence of group think within this generation and how shared perspectives develop in these circumstances. Given that a number of these responses could contain emotional elements it was decided that a follow-up exercise would be useful in exploring the idea of emotional engagement further. There would be indicated studies of both expectation of, and response to, the task. This second investigation would explore the ideas of uncertainty and response to feedback, exemplified in the response to unexpected outcomes of the simulation. This uncertainty was likely to be highlighted where the initial results from the first round of the simulation were not as good as the participants would have hoped. The participants were given a 
short questionnaire which was designed to elicit open comments to the questions given below:

Based on your performance how do you feel now?

Slightly better-- Yes slightly-- confused but start to understand the aim of the game-- ok, however unhappy we didn't win because we entered emergent markets only-- like some loser-- confused and negative as I have no idea what went wrong and how to improve-- No I feel the knowledge I had was obviously wrong-- confused, but start to understand the aims of the game-- I could have done better-- Not amazing, as the system failed to recognise our inputs at one point which meant our drastic actions that could have made us win came into action too late-- No because there is no way of applying it to a real company, it's hard to get a feel for anything when it's just numbers on a screen-- I felt fine after the first few rounds, but disappointed in round 3 results-- I feel much more confident in using simulations and how to change certain aspects to influence the final result-- Not that great but still confident that our stock price can increase-- Feel that our strategy was wrong and we should have perhaps taken a more aggressive approach-Disappointed after a strong start-demotivated with the continuous decline in stock price and market share Annoyed as our market share has plummeted drastically, also demotivated - Not good we have decreases in market share massively - Disappointed - Disappointed, we started well but our strategy wasn't as aggressive as others - Tired hungry numb soulless - Disappointed and frustrated - Disappointed about our group's performance - I feel very confused - Very disappointed with the overall position of the company Distraught that we haven't managed to turn the company around, still struggling to understand where it all went wrong.

What was your response to poor performance (if any) of your company?

Unhappy yet we had a very strong position in the market and should have come first-- review previous decisions, amend these and invest more, see where we went wrong and make changes-mostly confusion as we felt our ideas would have benefited the organisation and the consumer. I felt that the other groups should have shared their views and decisions, It was very frustrating as our decisions seemed to have no effect despite us putting a lot of time and effort into our decisions-- Horrible I want to cry-- We need to relook at our strategy and think about changes we make more carefully. Perhaps look at data and analyse more. Do better-- My response was negative, as I was not aware, or did not have the ability to put it right or improve the performance in the next round - How did it occur how can we fix it - Reduce costs, look at competitors - Disappointment Tried to cut costs down - Increase production Panic/Recklessness[sic]/ find cause of problem and solve Frustration - Proved the importance of market share positioning, doing well from a poor position - From stone cold bottom to $3^{\text {rd }}$ in the last year - Focused on a few key brands and markets pouring more money into advertising and sales force for those - Pleased to have pulled off a third place finish.

Do you understand what has gone wrong?

Didn't really think about the numbers-- We did not use any budgets, targeting too many markets-- Yes apparently we did the wrong thing-- we understood that we needed to improve sales

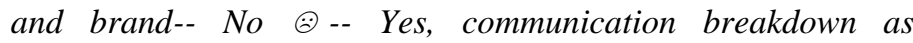
simulation got more complicated-- Not really-- After miscalculating the first period, I feel that this led to our downfall and that problems with the system that didn't allow us to access the $R \& D$ section until much later in the process-- We didn't evolve with the market quickly enough-- We were too conservative early on-- Yes we didn't do anything to improve our standing, but just in maintaining what we had. We accidentally withdrew a product-- Yes I invested a bit too much in a declining market which didn't work out-To a certain point- Wrong market segment changes in operations incurring unnecessary costs while not getting revenues -costs, more aggressive competition, targeting wrong segment - Our costs are too high - Totally rebranded when we didn't need to, people clicking without thinking, not looking at all the graphs - We targeted the wrong markets in the wrong rounds, also we sold out of units multiple times - Some parts yes - Yes not enough units sold - Although we may have made some bad decisions throughout the process I feel the group previously did not stand us in good stead - We didn't produce enough products and look at forecast - We didn't pay enough attention to the marketing forecasts provided - I believe the group we took over from are the main cause of our problems due to the wrong target markets. In addition I believe we didn't look into the forecasts in much detail causing the issues to multiply.

What do you need to improve?

Careful analysis and planning-- We have to do more on power-- We need to target the price and power, target fewer markets-- brand positioning, covering all the markets-- change decisions-- brand and sales-- I feel that I really do not understand the fundamentals of marketing. I therefore need to read and learn about marketing in general-- $R \& D$ in relation to target audience. Didn't fully invest in market when we had the opportunity to dominate that market-- not sure-- be more organised etc-- enter the new market-- We need to focus on one segment with our side product, rather than split it between two segments-- How to convert numbers and refer to numbers from the last period in order to make a good decision for the next period-- Enter a new market-- Think I need to look into market positioning more and what can affect it-Understand the market segments better - Define target segment accurately, run operations according to demands of the target segment - Reduce costs and increase sales to be able to increase ROI and market share, target another market - On spending according to our budget - Do not totally change target market when one brand is doing well - Pay more attention to the market forecast - Base future experiences on problems that were faced today - critical and strategic thinking - We need to think about our decisions more and not change our target market in the closing stages of the simulation - Don't try and fix something that isn't broken Put more money into advertising, stayed with a successful product-More detailed discussions and look into the details of the task closer in order to make more strategic decisions.

Did your understanding improve?

Yes slightly (2 times) - Yes (17 times)- No, I feel the knowledge I thought I had was obviously wrong - it depends, in certain areas as some problems require lateral thinking while 
other need to be thought about [in] more detail - No because there is no way of applying it to a real company. It's hard to get a feel for anything when it's just numbers on a screen - Yes because this gives me a bit more of an insight to real world marketing and the decisions taken in a business - It has a little, how quickly price product and market segments can change so quickly - Yes understanding of figures and relation between sales/price (positioning maps) - Not really, [I] think it will do with time but after period one has not had enough time to see changes - disappointed after a strong start - Yes a lot - I am starting to understand all the decisions businesses face Definitely improved - To a certain extent.

\section{DISCUSSION AND CONCLUSSIONS}

The results of this investigation into participants' responses go some way towards elaborating the nature of student engagement in the simulation as a form of situated learning. It employed an exploratory and iterative methodology that enabled the initial questions to be refined and developed. As a result of the initial exploration of the learning situation it is noticeable that there is certainly an expressed anticipation about what might happen in the use of the simulation. The evidence of performance is more visible and immediate in the conduct of such a public exercise which may increase the uncertainty, risk of failure, and intergroup competiveness. Often the results of learning in taught sessions are communicated and assessed sometime after the event. In this exercise there is this element of immediacy attached to the results which require a quick response. There is constructed a competitive simulation environment whereby no one wants to lose at least visibly, those that are losing may become even more attentive. This can be interpreted from the comments received in the questionnaire that highlighted the response to perceived poor performance. The replies to the question 'Based on your performance how do you feel now?' generated a number of negative views. These were expressed as disappointment, demotivation, being distraught, and confusion. One participant found that it was hard to get a feel for anything. These comments seem to fit in with the concepts of activity theory of ambiguity, surprise and interpretation introduced above. It is this participation in the time focused activities of the simulation that gives rise to its mundane nature. Being thus 'of the world' gives rise to the reality of such simulations.

In general there was a tendency to offer mainly analytical comments to the questions about understanding and the actions needed to improve. Particular comments made were "...be more organised; understand the market segments better; we need to think about our decisions". So it may be inferred that there is some move towards the development of expertise in response to this question and a consequent need to develop understanding further. So whilst the activity system in Ref. [7] used an expert activity system here there seemed to be the development of expertise although the emotional responses to the exercise were negative.

It can be noted that the phasing of the questions tended to govern the nature of the response. 'What was your response' tended to generate personal comments, whereas 'do you understand' tended to encourage reflections on the group performance; but both of these were present. One said there was 'communication breakdown' but general reflection on dialogic communication was not overt. Perhaps because these were people who had undertaken other group activities before this simulation exercise. Perhaps the nature of the simulation as an artefact tended to discourage the group communicative aspects. It was the technology that drove the interaction as opposed to the members of the group. In contrast to the comments about understanding there was a large amount of negative emotion connected with the question about their response to poor performance. Confusing, frustration and disappointment were statements that were noticeable. One respondent wanted to cry. There seemed to be a difficulty in knowing what to do here - in this activity - which could have generated the negative emotions. So as such the operation and interaction with the simulation generated this aporia. As such the engagement of emotions 'negatively' in the above scenario was found to be a vehicle to utilise this important dimension of learning [27] and to generate attentiveness to enrich understanding [14]. As an artefact the simulation was noticeably generative of this situation which would not have occurred in a traditional lecture format. This quotation that said 'it's hard to get a feel for anything when it is just numbers on a screen' seems to illustrate the point well. Yet when the students anticipated their performance in the activity it was the reality of it that was prominent. This reality was dissipated by a perception of computer problems and perhaps more importantly by the acceptance of poor results. Failure was not due to the reality; reality could be where anyone fails, but often put down to poor judgment.

The understanding of what went wrong was generally limited to negative comments usually about the group performance. 'What we did wrong' was the form of the comments. There did seem to be a group emphasis in this learning and the collective expression of poor performance could be evidence for dialogic learning as discussed above. It seems also to fit with the Generation Y need to feel connected with group decisions [13]. One group confessed to 'communication breakdown'. There was a view by one respondent that system problems detracted from any learning. This seems to reinforce the interpretation of this exercise in terms of activity theory. Artefacts should be accessible by all; they should be used directly rather than a pseudo-object; and they could be available in diagnostic and explanatory models [7].

In response to the question about the improvement of understanding there was a general positive response. A majority of the respondents said their understanding had improved. A couple of those that did not blamed the artefact; 'there's no way of applying it to a real company; it's just numbers on a screen. These students seem to see it as a pseudo-object in the above terms. It is not really typical of real business.

This has been an exploratory study in the use of a marketing simulation in an undergraduate course. It has explored the concepts of dialogic reasoning, the use of artefacts in active learning and the exploration of a 'constructive reality'. It has also gathered some evidence for the occurrence of negative feedback that is generated in this type of forum. This has contributed to the agenda for further research identified by [34] in exploring why simulations were not viewed as more effective 
than case studies, service learning, and in-class discussions. It can be proposed that this emotional impact during the performance of the activity has a significant effect on learning that is not present in the activities above. This paper offers insights to the emotional reflection on negative comparative feedback via a simulation in a common arena. The proposition is that negative feedback (publicly) will increase attentiveness and learning beyond that of traditional feedback mechanisms that are not within the dialogic space. It has contributed to the call for further research on the contextualised nature of learning and the potential for ethnographic studies in this context [29]. Using the techniques of scenarios and survey has enabled an empirical exploration of the student engagement in this type of learning with technological artefacts. It was noted earlier that simulations could be used as assessment tools and that they work well with formative assessments. There was no attempt here to discuss the impact of the simulation on the quality of the assessment. This research was not designed to determine this but to concentrate on the process of engagement within the arena constructed by the assessment.

\section{FUTURE RESEARCH}

The aim of this research was to explore the role emotional engagement relating to a simulation learning experience. The findings highlight the emotional anticipation and responses resulting in negative emotions that confirm a deep level of learning. It is proposed that further research could focus on the custodial nature of the learning where there occurs an intergroup transfer of the company, and the influence of this on emotional engagement, perceptions of reality, and emotional acceptance of relative failure. In addition the perceived importance of making sure the next stages of performance of their company by takeover group are successful. This will make a further contribution to the intra-group dynamics of learning literature.

\section{REFERENCES}

[1] Anderson, J., (2003). The relationship between student perceptions of team dynamics and simulation game outcomes: An individual-level analysis. Journal of Education for Business, 81(2), 85-89

[2] Ashworth, P., \& Lucas, U., (2000). Achieving empathy and engagement: A practical approach to the design conduct and reporting of phenomenographic research, Studies in Higher Education, 25(3), 295-308

[3] Barnett, R., (1997). Higher education: A critical business. Buckingham: Open University Press.

[4] Butler, J. A. (1992). The use of teaching methods within the lecture format, Medical teaching $14(1)$

[5] Crowe, C., \& Pemberton, A., (2000). 'But that's your Job!: Peer Assessment in Collaborative Learning Projects'. Proceedings of the 3rd Effective Teaching and Learning at University Conference, 9-10 November 2000. Brisbane: University of Queensland.

[6] Dickenson, J. B, \& Dickenson, C. D., (2012) The effect of Introducing coaching from an experienced business professional on performance in a computer simulation classroom exercise, Journal of Instructional Pedagogies, Vol.8, July,

[7] Engestrom Y., (1992), Interactive Expertise: Studies in Distributed Working Intelligence, Research Bullitin 83, Department of Education, University of Helsinki

[8] Engestrom, Y., (2009), Expansive Leaning in Illeris K., (Ed), 2009, Contemporary Theories of Learning, London, Routledge

[9] Exley, K., \& Dennick, R. (2004) Giving a Lecture: From Presenting to Teaching, Taylor \& Francis Ltd

[10] Germain, L., (2009). Global: MBA still in Demand despite recession. University World News, Issue 104, Dec, Accessed http://www.universityworldnews.com
[11] Hannon, J., \& Bretag, T. (2010). Negotiating Contested Discourses of Learning Technologies in Higher Education. Journal of Educational Technology \& Society, 13(1), 106-120

[12] Hermann, M (2010). Harnessing Students' Creativity and Imagination as a Means to Effective Engagement in Sustainable Education, Learning and Teaching in Higher Education (LATHE), Issue 5

[13] Hogg, D. (2013). Application of Groupthink to Generation Y Decision Making Processes within a Professional Services Context in New Zealand. International Journal Of Business \& Management, 8(8), 69-78

[14] Hope, M. (2009). The importance of direct experience: a philosophical defence of fieldwork in human geography, Journal of Geography in Higher Education, Vol.22, no.2, pp.169-19

[15] Jones O., McPherson A., \& Thorpe R., (2010). Entrepreneurship \& Regional Development, Vol. 22, Nos. 7-8, pp649-673

[16] Jones, S.E., (2007). Reflections on the lecture: outmoded medium or instrument of inspiration?, Journal of Further and Higher Education, 31(4), 397-406

[17] King, K. P (2000), The adult ESL experience: facilitating perspective transformation in the classroom, Adult Basic Education, 10(2), 69-90

[18] Klassen, K., and \& Willoughby, K. (2003) In-class simulation games: assessing student learning. Journal of Information Technology Education, $2,1-13$

[19] Kuhn, J. W. (1998) Emotion As Well As Reason: Getting Students Beyond "Interpersonal Accountability", Journal of Business Ethics, 17, 295-308

[20] Kupers, W., (2005), Phenomenology of embodied implicit and narrative knowing, Journal of Knowledge Management, 9(6), 114-133,

[21] Lainema, T., and \& Lainema, K. (2007) Advancing acquisition of business know-how: Critical learning elements. Journal of Research on Technology in Education, 40(2), 183-198

[22] Lucas, 1998. Cited in Mortiboys, A., (2002), The emotionally intelligent lecturer, Birmingham, SEDA.

[23] Markstrat, (2012), at; http;//www.stratxsimulationsonlinehome.aspx

[24] Marton, F., \& Saljo, R. (1976), On qualitative differences in learning Outcome and. process, British Journal of Educational Psychology, 46, 4-11

[25] McLean, R., Oliver, P. G., \& Wainwright, D. W. (2010). The myths of empowerment through information communication technologies. Management Decision, 48(9), 1365-1377

[26] Mezirow, J. (2009), An overview on Transformative Learning, in Illeris K., (Ed), 2009, Contemporary Theories of Learning, London, Routledge

[27] Mortiboys, A., (2002), The emotionally intelligent lecturer, Birmingham, SEDA.

[28] Neely, P., and \& Tucker, J (2012) Using Business Simulations As Authentic Assessment Tools, American Journal of Business Education, $5(4)$.

[29] Phan, H. P., Maebuta, J., \& Dorovolomo, J. (2010). The Relations between Personal Epistemology and Learning Approaches in Sociocultural Contexts: A Theoretical Conceptualization. International Journal of Learning, 17(5), 465-478.

[30] Prasolova-Førland, E. (2004). Virtual spaces as artefacts: Implications for the design of educational CVEs. International Journal of Distance Education Technologies, 2(4), 94-115.

[31] Rose, J., Fuller, M., Gilbert, L,. \& Palmer, S., (2010) Transformative Empowerment: stimulating transformations in Early Years Practice, Learning and Teaching in Higher Education, Issue 5, pp56-71

[32] Salas, E., Wildman, J. L., \& Piccolo, R. F. (2009). Using Simulation-Based Training to Enhance Management Education. Academy Of Management Learning \& Education, 8(4), 559-573

[33] Tan, K., Tse, Y., \& Chung, P. (2010) A plug and play pathway approach for operations management games development. Computers and Education, 55(1), 109-117

[34] Tanner, J.R., Stewart, G., Totaro, M.W., \& Hargrave, M (2012) Business Simulation Games: Effective Teaching Tools Or Window Dressing?, American Journal of Business Education, 4(2), 115-128

[35] Taylor, E. W. (2007). An update of transformative learning theory: A critical review of the empirical research (1999-2005) International Journal of Lifelong Education, 26, 173-191. 
[36] Williams, E (1992) Student Attitudes towards approaches to Learning and assessment. Assessment and Evaluation in Higher Education, 17(1), 45-58

[37] Willis, P. (2011). Utopian scenario sketching: An imaginal pedagogy for life giving civilisation. Australian Journal of Adult Learning, 51(3), 479497
[38] Yadav, M. S., \& Varadarajan, R. (2005). Interactivity in the electronic marketplace: An exposition of the concept and implications for research. Academy of Marketing Science Journal, 33(4), 585-603 